




\section{On the Modern Mimesis of Nature Networks, Tools, and Ecological Thought Albert Pope}

The rich relationship of architecture to nature has been gradually impoverished and narrowed down to a single mode of operation according to which the former imitates the forms of the latter. This use of nature as a repository of forms to be appropriated corresponds, one to one, with the logic of resource extraction that lies at the root of the current ecological crisis. In this essay, Pope tracks several architectural and urban responses such crisis, proposing a specific definition of the idea of organicism as a model of intervention in the natural world based on processes of functional integration.

\section{KEYWORDS}

Nature, Architecture, Imitation, Ecological Crisis, Organicism

\section{PALABRAS CLAVE}

Naturaleza, arquitectura, imitación, crisis ecológica, organicismo

INTRODUCTION: IMITATION TRANSFORMED
The deeply-rooted mimetic traditions of architecture and urbanism suggest that nature is the ultimate frame of reference for the built environment. Following a trajectory from the Corinthian column, to the Vitruvian Man, to Marc-Antoine Laugier's Primitive Hut, to Claude Nicolas Ledoux's House of the River Surveyor, to Frank Lloyd Wright's Fallingwater, the imitation of natural phenomena has long granted legitimacy to the otherwise arbitrary forms of our own invention. While the relationship between architecture, urbanism and nature has changed dramatically over the course of history, the need to reference natural forms in the environments that we build has been unwavering.

\begin{abstract}
Albert Pope
Gus Sessions Wortham Professor of Architecture at Rice University. He holds degrees from SCl-Arc and Princeton, and taught at Yale University and SCl-Arc prior to Rice. His design work has received numerous awards including national and regional awards by the American Institute of Architects as well as a design citation from Progressive Architecture. He is the author of the book-length study of the postwar American City, Ladders, recently reissued in a second edition (Princeton Architectural Press, 1997, 2015). Professor Pope has written and lectured extensively on the broad implications of post-war urban development. His current research addresses the urban implications of climate change. $\mathrm{He}$ is actively working on the formulation of new models of density in light of the extraordinary demands placed on the global urban environment.
\end{abstract}

Fig. 01

Venturi, Scott Brown and Associates Times Square proposal, unmotivated sign, 1984, Postmodern Imitation. 
Today, however, that relationship has entered a new and unprecedented phase typically evoked by the declaration of a new geological era, the Anthropocene. Acknowledging human activity as the dominant force in the ongoing transformation of the planet, the Anthropocene suggests that whatever our relationship to the natural environment has been in the past, it has become something quite different today. The growing awareness of our ruinous effect on the planet questions whether the mimetic traditions of architecture and urbanism can possibly continue and, if so, how they must be transformed in light of the present crisis.

This essay will attempt one answer to this question by tracking specific attempts of architectural and urban designers to reference the natural world through a process of functional imitation known as organicism. As it turns out, an architectural and urban response to the climate crisis, like the climate crisis itself, has been a long time in the making.

This response can be succinctly stated. The functional imitation of nature requires a shift of emphasis from the object itself to the relationships between objects. For decades, both urban and environmental thinkers have repeatedly advised us that the study of relationships are of principal importance. While we may admire the beauty of a five-thousand-year-old bristlecone pine, just as we may admire the beauty of an ancient religious monument, the extraction of a natural or man-made object from their natural or urban context misses their greater role amongst a set of interconnected objects and agents. In other words, if we extract the features of an ecosystem or a city from the environments in which they exist, we become blind to their ultimate purposes. While these arguments have largely succeeded in environmental circles -practically the entire world understands the idea of an ecosystem- they have had a limited effect on architectural and urban discourse. We continue to focus on, if not fetishize, the isolated architectural object in all of its splendid isolation.

To be sure, keeping a focus on architectural objects as opposed to relationships between architectural objects has had a beneficial effect on the discipline, especially in the rendering of cultural institutions. It has, however, made it difficult to construct a convincing urban idea and all but impossible to engage with the natural world. The shift of focus from objects to relationships is important to the understanding of the built and natural environments, but it becomes indispensable when the goal is to correlate the two.

Perhaps this shift of focus is self-evident; designing a stadium that looks like a seed pod or a bridge that looks like the wing of an insect, gives imitation a bad name. These object-to-object translations -seed pod to stadium or insect to bridge- produces the kind of one liners that invite affectionate nicknames accompanied by disdain from all quarters. To say the very obvious, the drastic realignment of the built and natural environment that we need to confront today requires a more sophisticated approach to imitation. The limitations of pods and bugs are precisely the limitations of extracting objects from their native contexts. Today, imitation requires a shift from the design of independent objects to the design of interconnections between dependent objects. By acknowledging, along with the rest of the world, that there is no such thing as an independent object, these interconnections can finally be exploited through a "functional" imitation of nature. 


\section{EXTRACTION}

It is not a coincidence that our mental habits reflect the priorities of the extraction economy. To focus on an object of nature, such as a tree or a fish, already performs a mental process of extraction. To think of nature as an object frames its meaning by removing it from its larger environmental context. Like trying to understand the function of a hammer in a world without wood, nails, or carpenters, an extracted object lacks a context capable of revealing the terms of its existence. In this way, extraction alone performs a complete transformation of urban and environmental objects in the direction of discrete entities or commodities.

While extracting an object from its context produces an estrangement between that object and the world from which it came, it also makes it easier to understand and make reference to that world. The function of a synecdoche -a figure of speech in which a single part is seen to represent the whole- is a significant aspect of traditional imitation. The simplification of natural forces to a series of discrete objects or signs capable of evoking all of nature has been a staple of communication going back to the most primitive of languages. On the one end is what is called an unmotivated sign. A body, an island, or a tree are examples of representative objects or parts that are capable of evoking rich associations, like the maple leaf that represents all of Canada or a big apple that has represented New York for over a century. These unmotivated signs stand opposed to what linguists call the motivated sign. Motivated signs are characterized by a functional relation between signifier and signified. What this means is that the sign is similar in the structure and organization to the object that is signified. For example, the 2011 the Qatar National Convention Centre by Arata Isozaki ironically associates a triangulated structural frame with a 'Sidra Tree'. There is a correlation between its function (the lateral stability of the frame) and its meaning. A unmotivated sign reproduces the way a signifier looks while a motivated sign reproduces the way a signifier functions.

Both of these projects use extracted natural objects to produce urban icons for Manhattan and Qatar. Perhaps the most important aspect of such objectifications is that they translate nature into terms that are directly comparable to our own production. The long history of analogous associations between the objects of nature and objects of our own making is significant. In many ways, the history of analogous,
Fig. 02

Arata Isozaki, Qatar Convention Center, motivated sign, 2011, Postmodern Imitation.

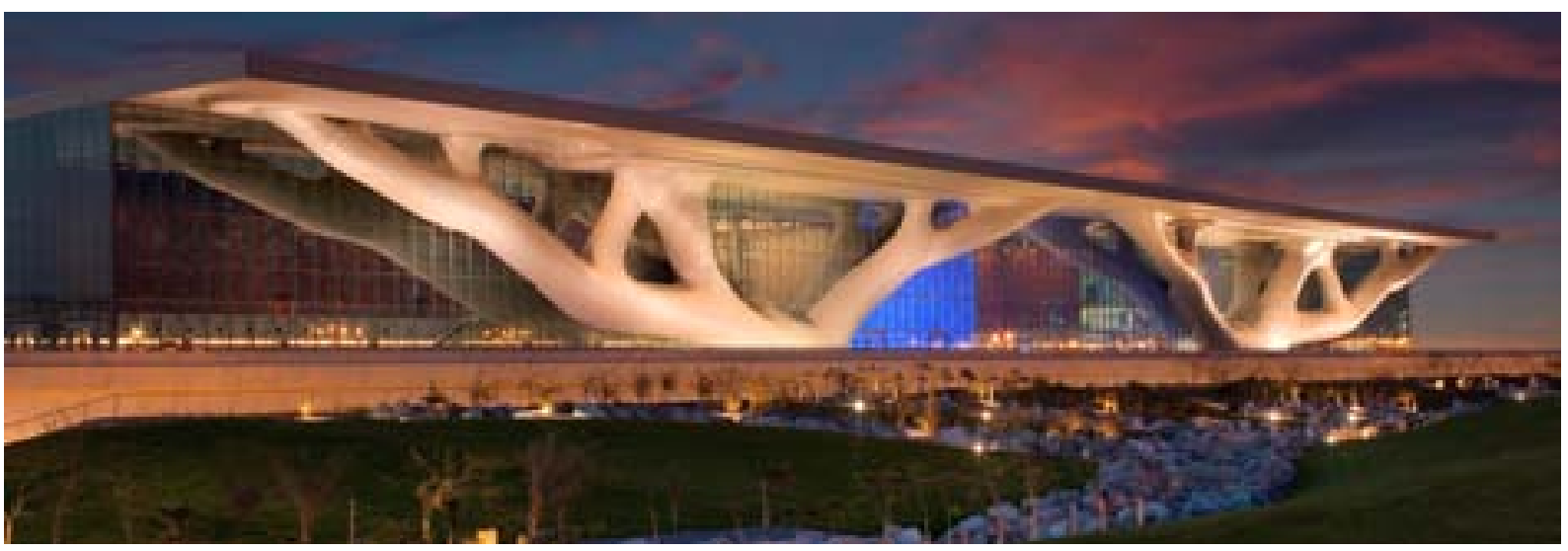


Fig. 03

Zaha Hadid, Tokyo Nation, 2012.

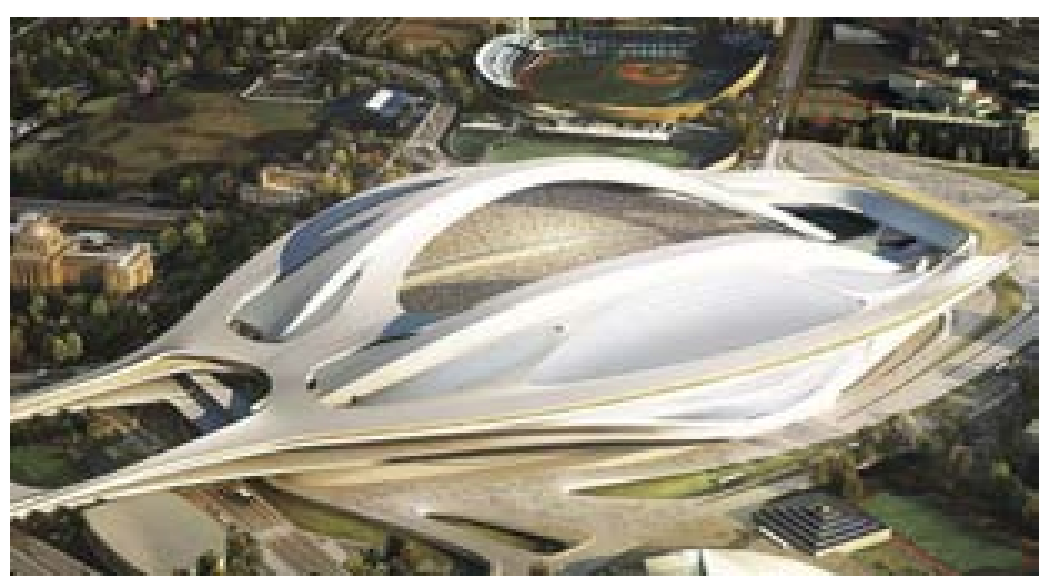

03

object-to-object associations is the history of "mimetic" form-making. The Corinthian order is analogous to an acanthus plant, latin-cross plans are analogous to the human body, the graded rustication of a classical elevation is analogous to geological sedimentation, hypostyle halls are analogous to forests, and pools and gardens are analogous to natural landscapes. The list of mimetic form-making across history is long.

Such mimetic strategies crossed over into modernism. Frank Lloyd Wright directly associated the core of a modern high-rise building with the trunk and branches of a tree and he designed a museum in the shape of a nautilus. Louis Kahn imagined the freeways of Philadelphia as analogous to rivers, streams and tributaries. Postmodernism brought about the two ironically laden urban signs mentioned above. Today, we are awash in unacknowledged object-to-object associations with the natural world. Once dismissed as a minor branch of the modern movement, "expressionism", has undergone a revival opening the door for traditional mimetic strategies. Today, institutions of all sorts are routinely based upon the outward appearance of root vegetables, seashells and insect wings, all serving to architecturally embellish our distended urban landscapes. And those landscapes, too, are driven by object association. Spine based urban developments were associated with leaves and trees by Team X, while clusters of gated communities are today likened to archipelagos. Imitations endure, yet these traditional and contemporary associations are based upon conceptual extractions which turn out to be far less innocent than they first seem.

POLARIZATION

Object-to-object analogies -stadium/seed pod, Latin cross plan/human body, high-rise/tree, campus/island- are generative and, over time, they have brought a limited degree of effective association between the natural and the man-made world. In this regard, nature remains a powerful authority, an authority that links the innocent apple in Times Square with the corporate greenwashing of fossil fuel corporations. To take the most obvious examples, British Petroleum has a beautiful green Helios logo flying over the cleanup operations in the Gulf of Mexico just as the Shell Oil Company has its trademark red and yellow shell logo emblazoned on drilling rigs above the newly thawed arctic circle. These 
associations are made economically and politically potent by synecdochal extractions. But to the extent that these icons are compelling, they are, to an equal degree, reductive. Extraction from nature produces an estrangement between the extracted objects and the rest of nature, including ourselves.

This estrangement is routinely attributed to the muchmaligned Cartesian split between mind and body, self and world, and nature and culture that many ecologists today identify as the source of our profound alienation from the non-human world. Amongst the many binaries that occupy our inescapably dualist worldview, few have been as damaging as the opposition of nature and culture. While dualism is not intrinsically negative, however, it too often lapses into opposing poles that eliminate all shades of interaction that can exist between them. In other words, dualism is not the problem, the problem is the reductive polarization that eliminates the potential interrelationships that occupy its excluded middle ground. To risk a gross simplification, objects dwell in the extremes and relationships amongst objects dwell in between. The inability to discern these relationships is problematic for design inasmuch as the middle ground between the natural and cultural domains is where most of our actual design challenges exist and where their potential interactions with the environment can be found.

The polarization of nature and culture also gives us the cultural space with which to regard nature as an ideal that is external to our routine, man-made existence. The objectification of nature as some whole leads us to enshrine it in hermetic vitrines, in natural history museums and in natural parks and reserves. (With such partitioning, nature is not something we live in, or something that we are, but something that we isolate and revere in an ideal state.) In these examples, nature is extracted materially rather than semantically, but in both instances, the polarization is in play. Through the process of environmental extraction, we cleanse nature, turning it into something that is unadulterated, remote, rarified and precious. By sequestering the natural within the boundaries of a terrarium or an atrium, or a park, we give ourselves license to disvalue every form of nature that falls outside of those boundaries. In other words, those many instances of the middle ground, that meld the natural and the cultural are defined as something apart from the ideal nature that we otherwise revere. All that is not isolated -more than $85 \%$ of the earth's land mass $99 \%$ of the sea, including the Gulf of Mexico- becomes an expendable resource that humanity can plunder with impunity. The objectification of nature gives us the conceptual license to carry out this plunder.

From the Shell logo to the Yellowstone National Park, the extraction of natural objects from their functional interrelationships gives rise to an understanding of nature that is simultaneously useful and alienated. In the short term, this estrangement has served humanity well, providing seemingly unlimited resources along with a convenient cultural alibi with which to fully exploit these resources. It is precisely this estrangement that has allowed us to build up an anthropocentric world order that has come to imperil so many of the planet's natural systems. Now seventy years into its existence, Anthropocene has simply confirmed what we already knew, that humans have approached a scale of technical prowess as to destroy the very conditions on which their prosperity and survival depends. 
At this late stage of the game, does it remain possible to subvert the polarization of nature and culture? Could such a subversion be promoted through the mimetic practices of architecture and urbanism? Can the built world imitate the natural world without going through the deleterious process of object extraction? These questions are by no means new, but they are newly pressing.

ON NETWORKS AND TOOLS
Hammer, tongs, and needle, refer in themselves to steel, iron, metal, mineral, wood, in that they consist of these. In equipment that is used, 'Nature' is discovered along with it by that use". - Heidegger, "The Being of the Entities Encountered in the Environment"1

The perils of extraction and polarization have been known for some time, and the call to shift our emphasis from objects themselves to the relationships between objects has come from many quarters. Following from the example of natural networks such as ecosystems or man-made networks such as the internet, network theories have given prominence to the importance of interrelationships between objects of all kinds. Going back to the eighties, Actor Network Theory, known by its acronym ANT, pursued a critique of the objects from the broad perspective of the natural and social sciences. Developed by science and technology studies scholars Michel Callon and Bruno Latour and the sociologist John Law, ANT is more a method of analysis than it is a consistent theory. It attempts to describe the social and natural worlds as a series of networked relationships that have two distinctive properties. The first is that contemporary networks are comprehensive, no man-made or natural object can exist outside of them. The second is that all elements in the network are on the same level, constituting what has since come to be known as a "flat" ontology. In a flat ontology, all of a network's constituent elements -animate and inanimate, human or nonhuman- are of equal importance. This characteristic gives rise to heretofore unimagined heterogeneous networks that nonetheless resemble the networks of which we are a part. These networks can include policies, trash, weather, tea bags, digital technologies, legal briefs, as well as jockey briefs amongst a long list of outmoded ideas that, because the network is flat, are all capable of interaction.

Perhaps most important to the imagining of relations approach to architecture and urbanism is the definition of ANT as a "material-semiotic" method. What this means is that Actor Network Theory is concerned with explicating relationships that are simultaneously material -relationships between things- and semiotic -relationships between concepts. In short, it assumes that significant social relationships are always and already material and semiotic. This network is what anthropologists have long-called a material culture. Yet it differs from the majority of the human sciences in that it offers an approach which avoids essentialist extractions of objects, ideas or events.

Though it includes both semiotics and material actants, a typical ANT network seems more heavily weighted toward materiality. This bias is of prime importance to the designers of the built environment in that it elevates objects to something closer to their appropriate role in the order of things, yet it elevates this modest role in a network rather than as an isolated object or icon. Latour argues that, from a political 
perspective, "each object gathers around itself a different assembly of relevant parties. Each object triggers new occasions to passionately differ and dispute. Each object may also offer new ways of achieving closure without having to agree on much else. In other words, objects -taken as so many issues- bind all of us in ways that map out a public space" ${ }^{\prime 2}$. The imagination of architectural objects as the focus of political concern is heartening despite the fact that, by design, architectural objects are extracted and fetishized to the point that they are incapable of "gathering" anything, much less a public space. Like trying to understand the function of a hammer in a world without wood, nails, or carpenters, an object needs a context that is capable of revealing the terms of its existence.

SILENCING THE OBJECT

Throughout the nineties, this revaluation of material forms as key components in an actant network provided a seldom acknowledged backdrop to a growing interest in networks in architectural and urban discourse. There have been many attempts to shift the emphasis off of the object in favor of the network of relations that exist between human and nonhuman objects. Most recent attempts at articulating a program of relationships have been associated with what in hindsight appears to be a naive enthusiasm for a nascent digital culture. In these cases, network theory served as cover for a resurgence of digitally driven biomorphic formalism of which continued the tradition of object-to-object imitation of seed pods, clam shells and radiolaria that make up the practice of "parametricism" today. Others, however, approached networks in a more abstract and literal sense. In his seminal essay of 1997, "From Object To Field", Stan Allen found in the quasi-urban typologies of the Mosque of Cordoba, as well as in the ordering logic of minimalist art, valuable precedents for the displacement of design emphasis from the object to the field. The terms of this displacement could not have been made more

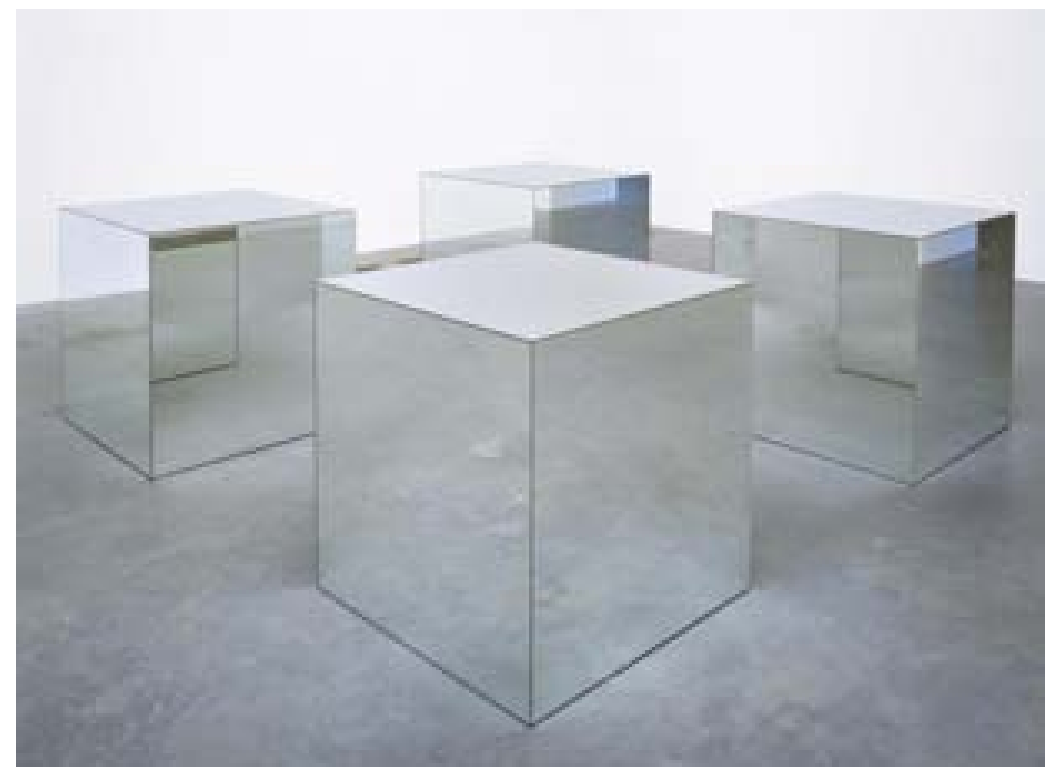

Fig. 04

Robert Morris, Untitled, 1965, from "bodyspacemotionthings", Tate Modern, 2009. Emptying the object of its figuratively or material character allows relationships between objects to be foregrounded. 
explicitly: "Minimalist work of the 60s and 70s sought to empty the work of art of its figurative or decorative character in order to foreground its architectural condition. The construction of meaning was displaced from the object itself to the spatial field between the viewer and the object: a fluid zone of perceptual interference, populated by moving bodies"3.

While many architects today practice in a minimalist "style", it is often employed in support of object fixation rather than in support of the relationships between objects. At its best, modern minimalism is about emptying the object of its figurative and decorative character precisely so the relationship between objects can come to the fore. Mies created minimalist buildings in order to emphasize the relationships between objects, and his many multi-building projects attest. John Pawson, for example, uses minimalism strictly as a style employed to fetishize objects, much like his repeat client Calvin Kline. That we have lost the ability to distinguish between the minimalism of Mies and the minimalism of Pawson is an indication of how far we are from shifting emphasis from objects themselves to the relationships between them. I will come back to this aspect of Mies' project later.

Despite the clarity of intent, the inability for architecture to move beyond fetishization is the result of two related problems. The first problem is the absence of a coherent and contemporary urban project. Since the collapse of modern urbanism in the 1970 s, no ideas at the scale of the city have risen to take its place. The best we have to offer are superblocks that attempt to imitate the outmoded urbanism of anthropomorphically scaled blocks and streets. This is perplexing given that the study of relations between objects, first and foremost, is a study of urban form. After all, cities, even more than ecosystems or digital networks, have historically been about the relationships between buildings rather than buildings themselves. It is the relationships between buildings that give rise to urban public spaces, for example. Without an active urban model in place, the city passes for whatever already exists, and the architectural job description is to produce monumental counterpoints within that already existing condition. This brings us to the second problem concerning our ability to employ the shift from objects to field: architecture's complete identification with the production of spectacular form. Despite the desperate need to shift from the architectural to the urban scope of design, we remain mired in the production of spectacular form, most recently identified as the "Bilbao Effect". While this effect shows no sign of waning, the luxury of limiting architectural design to the production of spectacular forms may already be behind us. The fact that many of today's pressing design problems cannot be answered by the deployment of isolated and spectacular form is lost on no one, save those who remain intent on producing them.

ORGANICISM 


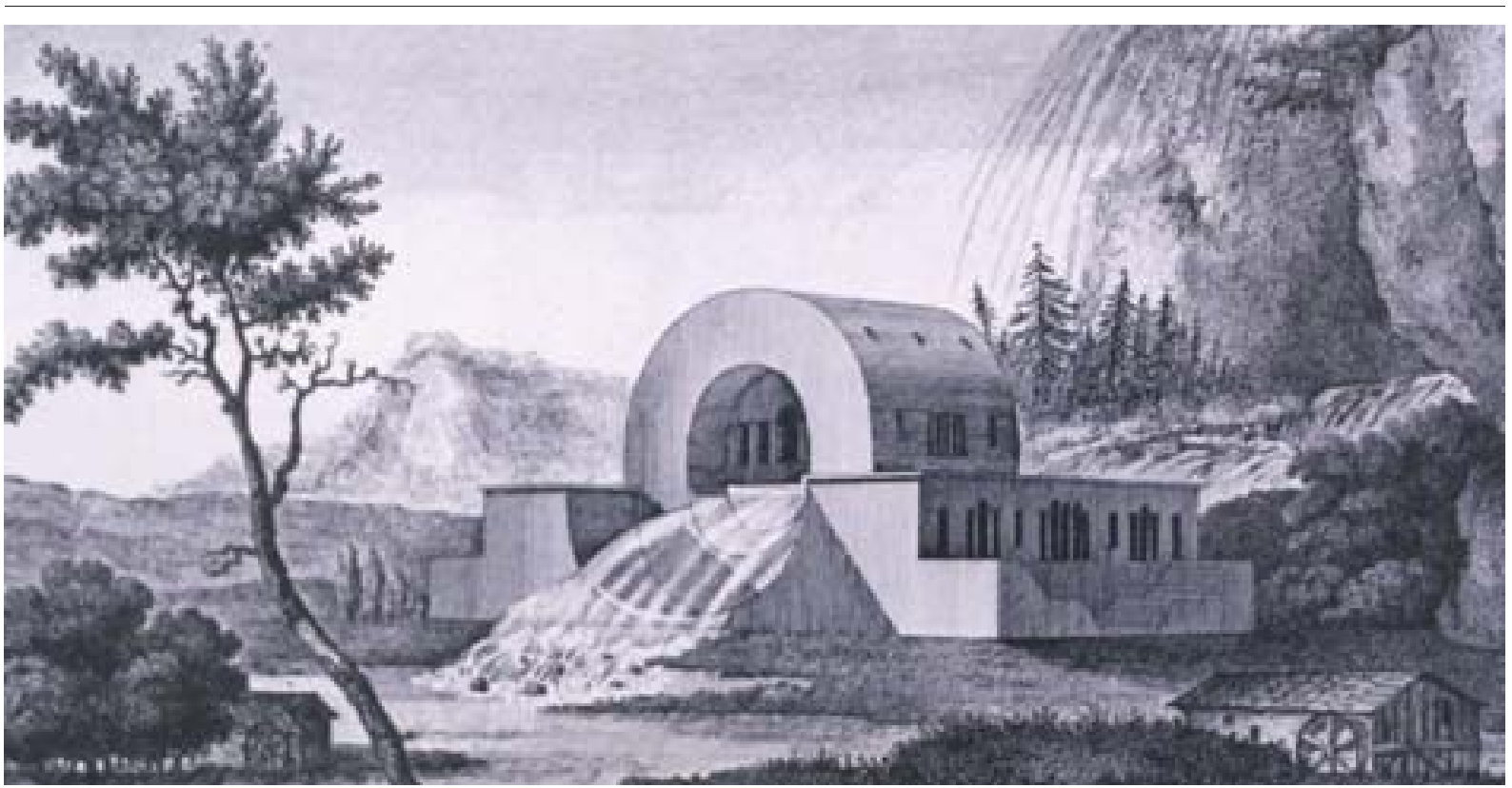

05

It is not a coincidence that our mental habits reflect the priorities of the extraction economy. As Jason Moore has said, in all simplicity, "capitalism is a way of organizing nature" is based on a process of commodification which extracts raw material from the networks in which they are embedded and transforms them into discrete objects of consumption. Our need to materially and conceptually understand the networks to which objects belong speaks to the importance of imposing limits on capitalist production. It also speaks to the revaluation of spectacular form-making. Moving beyond the extraction economy requires a cultural shift that eschews the crude objectifications of nature and culture as poles of a binary argument. Following the logic of the integrated ecosystem, design must come to imitate, not the objects of nature, but its intricate functional relationships.

Organicism, a term coined in Germany in the nineteenth century in order to describe nature's functional relationships, was explicitly embraced in the early years of modernism. In that context, organicism was understood as a mimetic strategy that does not use extraction and objectification as a way to imitate nature's outward appearance. Rather, it was interpreted as a process that imitates how nature functions within a complex and integrated network of relations. Leaving the traditional mimetic procedures of architecture and urbanism behind, modernism used the notion of the organism as a broad-based metaphor for an organization logic that integrates a complex set of parts into a whole. The ultimate model for this network of relations reaches back to the invention of the science of ecology, as the origin of all interconnected networks that have since been promoted. The contemporary idea of a network does not come from communication or transportation technologies or even the networking of buildings through urban infrastructure. These are all imitations of the networks that have been found operating in nature. These networks first came to be discovered and described in the nineteenth century science of ecology. By the turn of the century, these ideas had
Fig. 05

Claude Nicolas Ledoux, House of the River Surveyor, aka "the Drain". 
matured to the point of being widely understood and accepted. As such they began to have a broad effect on cultural discourses, including the discourse of modern architecture and urbanism.

ON HOLISTIC INTEGRATION
In light of new theories regarding nature's interconnected networks, modern architecture and urbanism looked toward strategies that were capable of imitating, not the isolated objects of nature, but its organizational logic. What nineteenth century science taught the first generation of modernists was that nature's functional logic cannot be drawn from objects taken out of context for the simple reason that nature was simply no longer conceived in this way. Once the idea of biotas and ecosystems reached a level of general awareness, iconic representation appeared to be antiquated, ineffective and incompatible with a modern worldview. What this meant for modernists was the need to update architecture's mimetic strategies. Under this new dispensation, the idea of the synecdoche -that the part could represent the whole- was no longer effective. Natural objects were no longer representative of a whole but had to instead be more accurately rendered as what they actually were: members in greater part-to-part and part-to-whole relationships. To meet this new model of imitation, the contemporary concept of organicism was defined, both in the sciences and in aesthetics as an update to an otherwise ancient logic that went by the name of holism. Described most simply by the trite slogan "the whole is greater than the sum of its parts", holistic organization became a way to sort out the part-to-whole problems that complex ecosystems were beginning to put forward as a model of natural organization. It followed directly that these part-to-part and part-to-whole problems would become central to a strategy of modern imitation.

In its simplest definition, organicism is the use of natural systems and, more specifically, the biological organism, as the ultimate model or template of architectural and urban form. I believe this correlation first came to light in Detlef Mertins's seminal 2001 essay “Living in a Jungle: Mies, Organic Architecture, and the Art of City Building". In the essay, Mertins describes the impact of organic processes on Mies van der Rohe -modernism's least likely protagonist of organic form-making. The fact that he is the least "organic" of the modern progenitors is precisely the point. In an attempt to transition from the imitation of how nature appears to how it functions, Mies's minimal glass and steel sheds -objects emptied of their "figurative and decorative character"- entirely eschew traditional imitation yet show how the mimetic strategies of the past came to be updated and extended. As such, his designs become ideal test subjects against which to isolate and define a modernist imitation of natural functions. Mertins writes:

Mies asserted that "the forms of cities are the expression of existing modes of living"; he went on to say that "they are inextricably bound up with these, and that they, with these, are subject to change. He described the role of modern urban planning as helping "the changed structure of our life find its corresponding expression" in an "organic form for our cities". Mies took the city to be the environment (Umwelt) with which architecture was bound up and, at the same time, its ultimate goal. It was a figure of totality and integration, symbol of the all-embracing but intangible structure, the unity of relationships and 
interdependencies between things that he sought to express in material form and make palpable for the beholder. Like many others of his generation, Mies invoked the figure of the organism to refer precisely to such a holistic and unified relational structure. Based on the organic principle of free relation among self-determined parts, the model of the organism could be applied to machines and machine-like cities as well as to plants (my emphasis) ${ }^{6}$.

Through reference to the biological organism with its "principle of free relation among self-determined parts", Mies and his urban pencil, Ludwig Hilberseimer, used the organic as the means toward an expanded, almost spiritual, idea of nature's function. Mertins retroactively theorized the exalted place of biological function in the formation of modern architecture using organicism to resolve the seeming opposition between natural forms and modern abstraction. An organic functionalism held that architecture should imitate, not the outward forms of nature but its fundamental (part-to-part) organization seen everywhere in the natural world. In this regard, parts should be arranged in such a manner as to produce a greater sum born of "interdependencies" between its parts and between its parts and the environment in which they exist. Understood as a deeper definition of function, this inner logic was reproduced as an extended network of interrelated parts.

Using an appropriately natural reference to describe the idea of holistic integration, Mies called attention to a single part or segment of the finger as an example. (You can make an iconic object out of an entire hand, but not out of one segment of one finger.) Mies referred to the relationship between each segment of a finger to the finger as a whole as a functional relationship. How the finger then relates to the other fingers and to the palm of the hand, to the wrist, forearm, and to the rest of the arm, created what Mertins referred to above as a "holistic and unified relational structure". The proportional relationship of part-to-part and part-to-whole spoke of an imitative functionalism operating within his and Hilberseimer's work and within the broader modern project as well. As a substantial correlation between design practices and the long-standing authority granted by the natural world, organicism provided a metaphor for an entity that is simultaneously relational and autonomous.

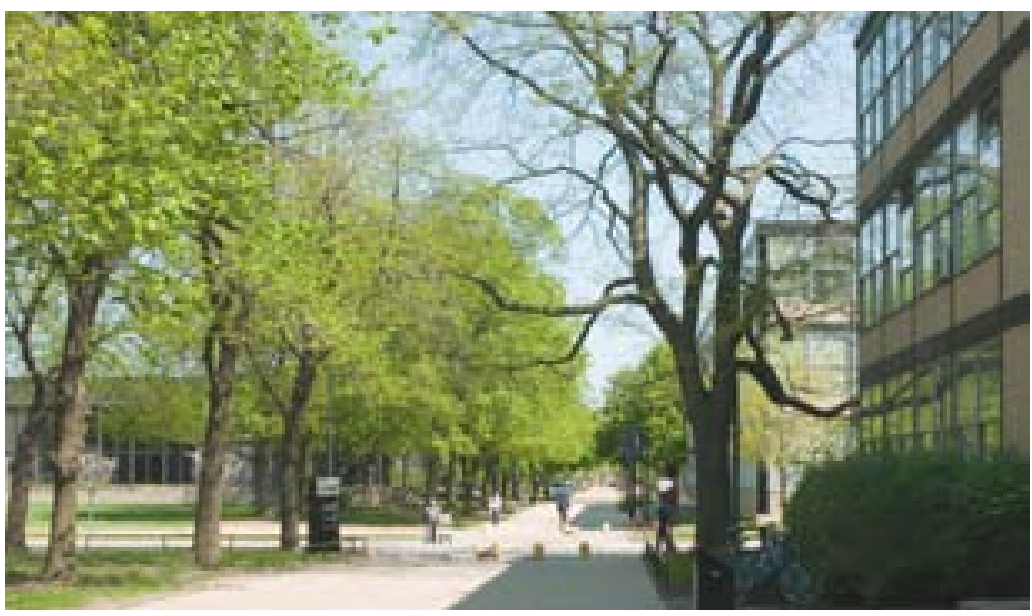


By embracing organicism, modern architecture embraced, not just a more advanced worldview emerging from the life sciences, but a new strategy that evolved out of a long history of natural imitation. Though it has largely been forgotten, modernism, especially modern urbanism, insisted on a wholesale revaluation of form that shifted emphasis from the object itself to the interaction between objects. As noted in the section above, the modern environmental object was emptied out of content in order to place emphasis on the relationships between objects. (A network in which the nodes were almost invisible.) The exquisitely balanced part-to-whole relationships found in Mies's great ensemble projects -IIT campus (1939-1958), 860-880 Lakeshore Drive (1949-1951), Lafayette Park (1956-1964), TorontoDominion Centre (1964-69), among the better known- simply cannot be understood apart from this willful shift of emphasis. While many modernists employ what must be called a minimalist "style", the elimination of figurative or iconic meaning is almost always used to fetishize isolated objects rather than enhance relationships between objects. Even in Mies's own work, his isolated objects, like the Seagrams Building, take a diminished (that is to say fetishistic) position within his body of work and did much to misrepresent his ultimate aims. At its best, the sometimes beautiful sometimes awful emptiness of minimalist form does more than constitute a willful stylistic choice. In allowing the relationship between objects to come to the fore, Mies and Hilberseimer were translating the ancient mimetic traditions into a drastically transformed scientific and cultural context.

Suspending traditional mimetic procedures -including the type of iconic and expressionistic symbolism that is prevalent in the apples, bugs and pods of today- the organic functionalists saw architecture and urbanism as an integrated network analogous to a living organism. Inasmuch as each organism possesses its own internal logic, its parts would also be autonomous or self-determined. Nevertheless, these relatively autonomous parts would also relate to each other forming an integrated whole. This delicately balanced part to whole relationship is nowhere more obvious than in a large scale urban proposal.

\section{AN INTERCONNECTED ORGANISM: NEW} ROCKFORD

The theory of architecture as the art of building (Baukunst), which Mies advanced here, was in fact founded on the principles of organic city planning. Like many of his generation, Mies understood cities to be synthetic cultural forms mutating over time through the interaction of historically specific forces. Cities were the ultimate expressions of society-in-the-making, products of the dynamic interplay of economic, political, social, and spiritual conditions. Mies asserted that "the forms of cities are the expression of existing modes of living"; he went on to say that "they are inextricably bound up with these, and that they, with these, are subject to change".(99) He described the role of modern urban planning as helping "the changed structure of our life find its corresponding expression" in an "organic form for our cities". -MERTINS, "Living in a Jungle: Mies, Organic Architecture, and the Art of City Building”.

Organicism stressed the adaptive relationship between the organism and the ecological context upon which its survival depended -survival being the primary "function" of an organism that has adapted over time to a specific environment. Key to this relationship is the scaling of the environment. While an environment has many scales, and one can always refer to a yet larger scale, the environment is singular. For this reason, among others, Mies and Hilberseimer sought an integration of ar- 
chitecture and urbanism as merely two different scales of a single actant network. Like an organism that knows no boundaries between itself and its context, the room in the building, the building in the city and the city in the region would be seen as a "holistic and unified relational structure".

Though it informs every aspect of Mies and Hilberseimer's work, it is important to tie their deployment of organicism to a specific imitation of organic "function". Keeping in mind that imitation does not distinguish between the architectural and urban scale, I would like to show the development of an interconnected field of self-determined parts in a relatively large-scale setting.

In the early 1950s, Hilberseimer produced a project for the phased redesign of Rockford, Illinois in its entirety. Rockford was, as it remains, a medium-sized town founded at the shallows or the "ford" of the Rock River. It no doubt pleased Hilberseimer to work on an urban settlement whose very naming was occasioned by the expedient confluence of the manmade and natural world. It is, indeed, such a functional interface between urban and natural systems that informs so much of Hilbersiemer's production, especially the Rockford plan, and sets it apart from the reductive functionalism with which he is so often associated.

Throughout their careers, Hilberseimer and Mies were aware that what we today refer to as ecology was regarded as a cultural rather than a technical problem. From Fallingwater to Lafayette Park, a cultural sensibility drives modernism's embrace of architecture's mimetic function. It is important to acknowledge that a cultural rendering of our ecological problems is at odds with the technical hegemony under which environmental discourse wholly operates today.

This technical hegemony is born of the polarization of the cultural and the technical. Like the opposition of nature and culture, this duality too has polarized into exclusive positions which allow for no middle ground. The imitation of nature is irrelevant to a strictly technical worldview, not because it is cultural, but because it poses a complex interrelationship between the cultural and the technical rather than a single pole. In other words, imitation is neither technical nor cultural but occupies that excluded middle zone of a polarized worldview that limits our ability to solve our most pressing problems. If a problem is technical, then it exists within the realm of the engineer. If a problem is cultural, then it exists within the realm of the artist. For too long, the problem of the city has been restricted to the engineering side of the equation with the occasional monument thrown off as scraps to the domain of culture.

Nowhere is the absence of the middle ground between the technical and the cultural been more keenly felt than in the specification of an "ecological" city. The urban project of Ludwig Hilberseimer attempts to open up this middle ground, addressing the city as a cultural as much as a technical problem. By way of introduction, Hilberseimer's project for the replanning of Rockford demonstrates the prospects of staking out new territory in this long-abandoned middle ground.

When considering the project documentation, the project's most important and unusual quality becomes immediately apparent. It is not based on a definitive "master plan" but is instead described as a series of phased states, each of which have their own particular interest. As opposed to delivering a single, emblematic composition, the Rockford plan, like all of Hilberseimer's later work, are about using time as a design medium. In the case of the Rockford project, the temporal logic 


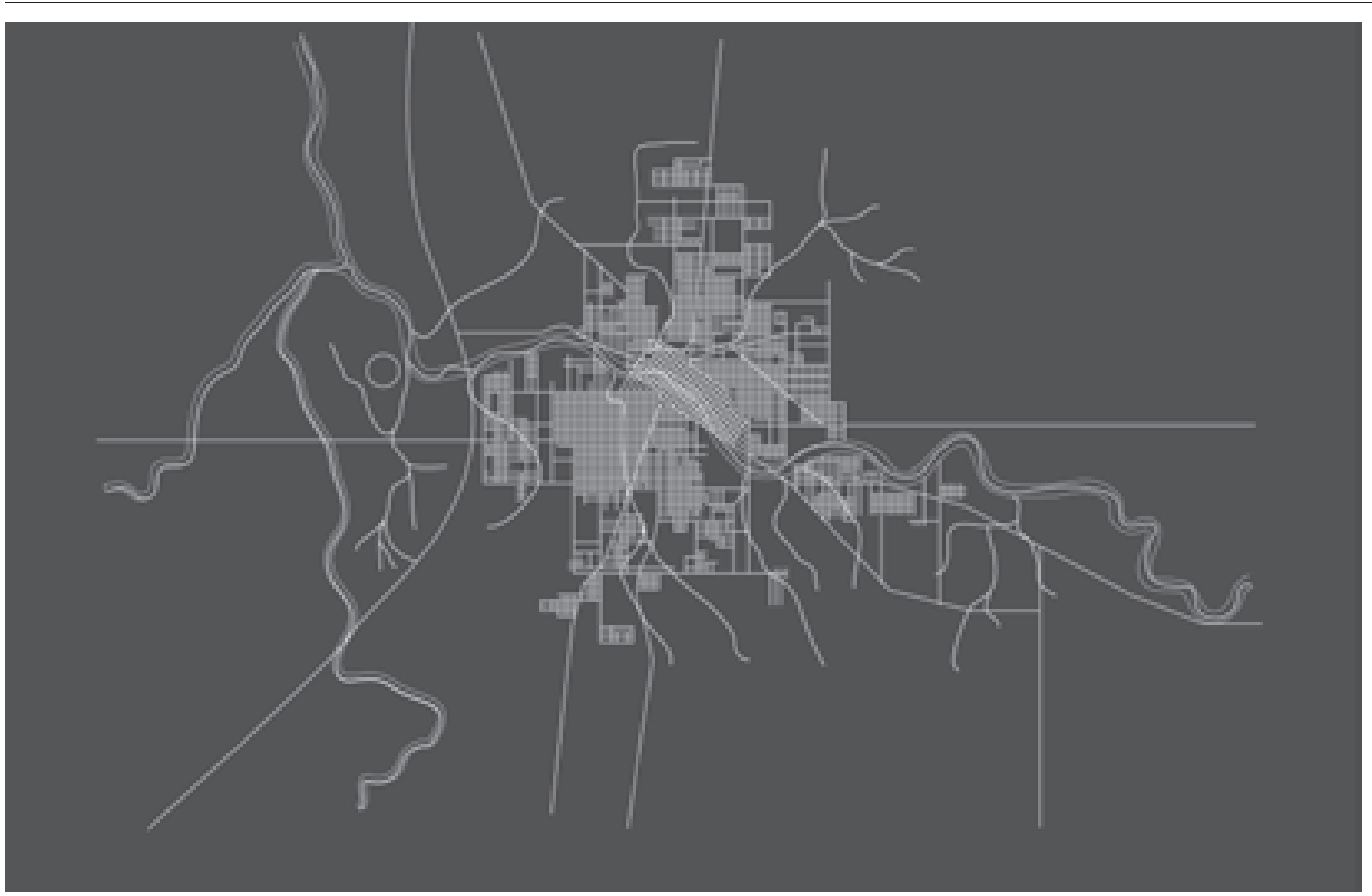

07

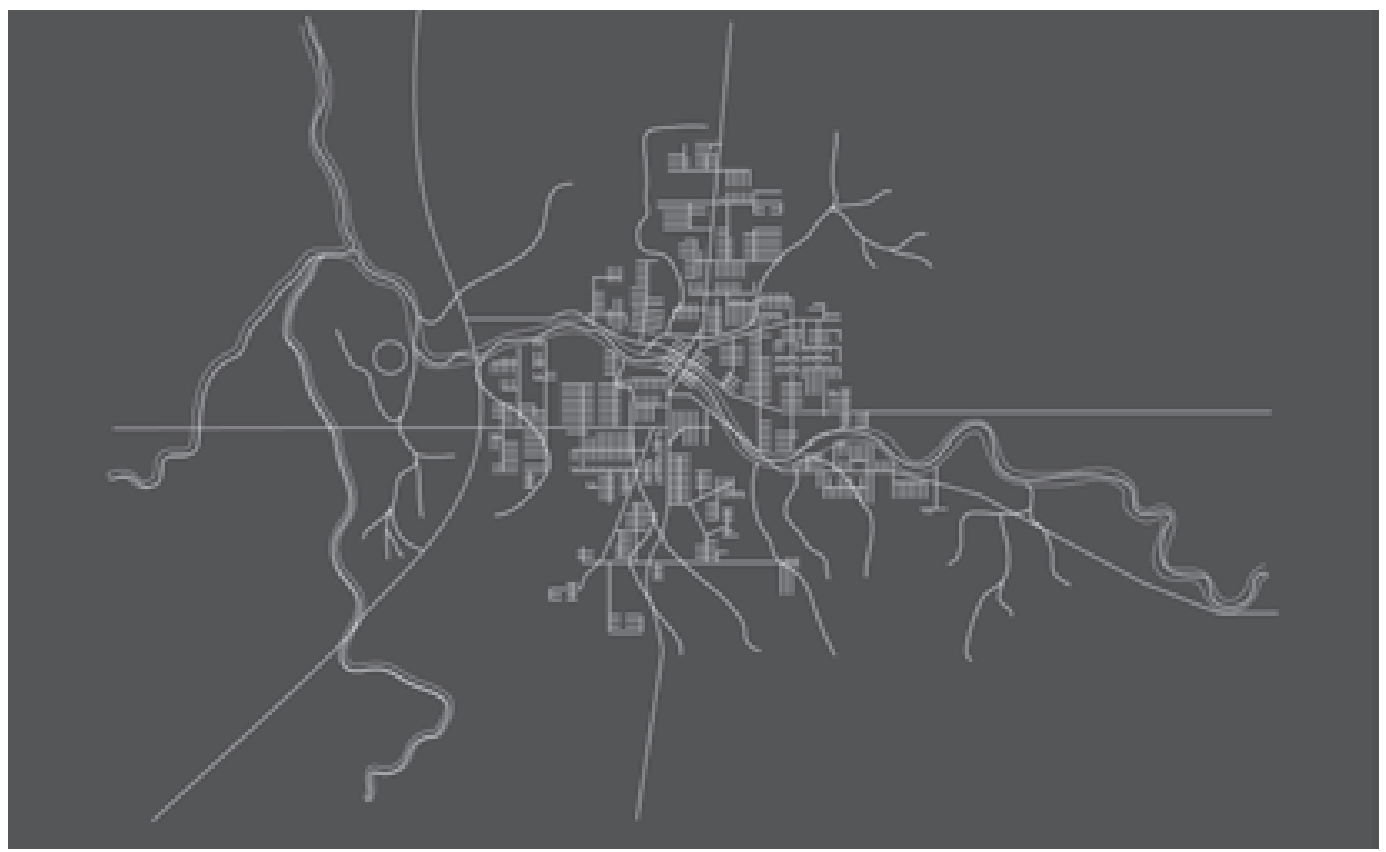

08

Figs. 07, 08, 09 y 10

Ludwig Hilberseimer, Rockford

Replanning; a) existing condition (closed

centralized city superimposed on a

linear riverine ecosystem); b) replanning,

phase one; c) replanning, phase two;

d) replanning, phase three. 


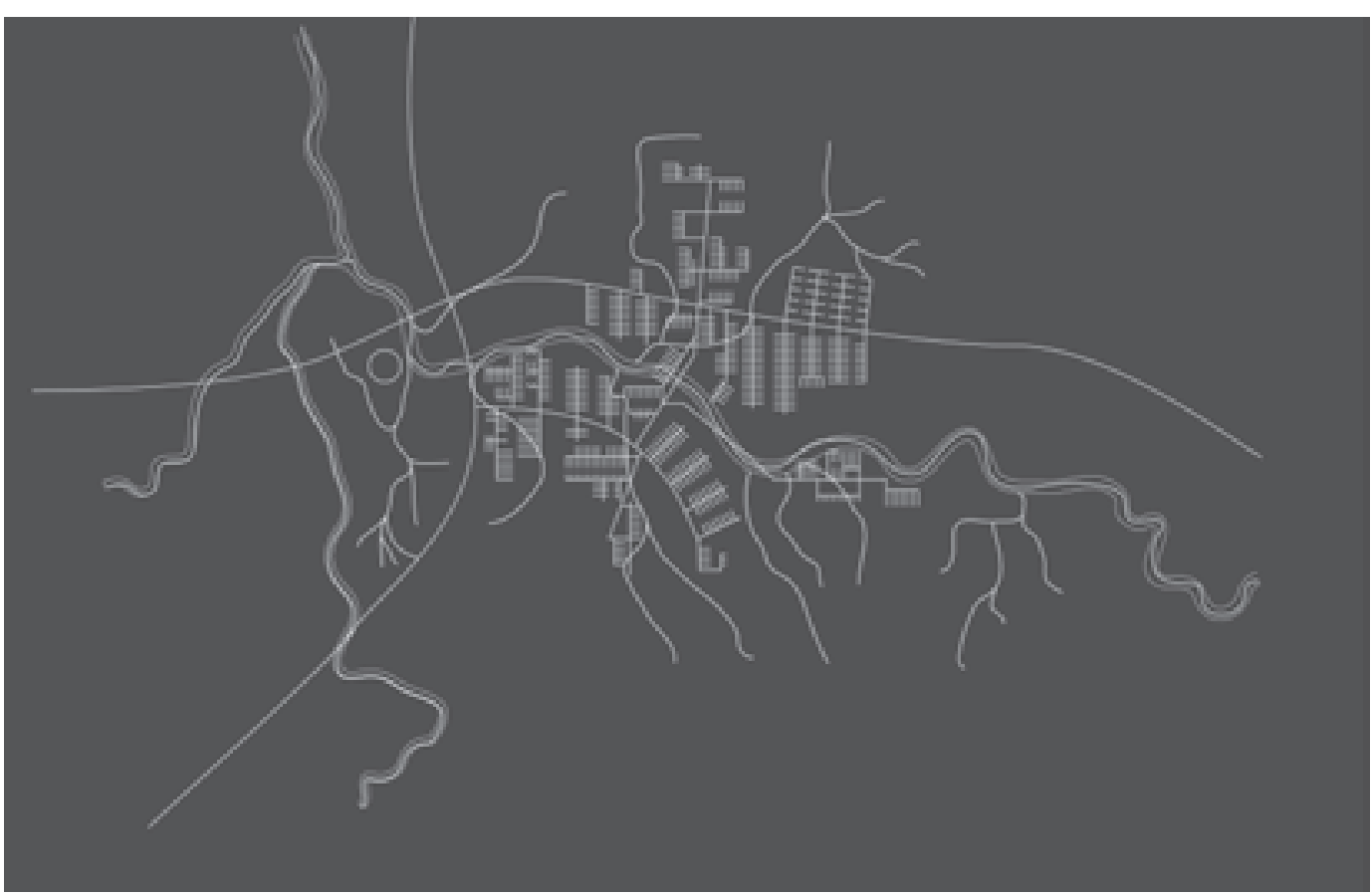

09




is shown in four sequential panels. The replanning of Rockford was not a tabula rasa proposition but was imagined instead as a series of discrete phases of demolition and construction, with each phase showing a unique settlement with differing degrees of continuity, differing degrees of unity and fragmentation, and differing degrees of openness and closure. New Rockford would emerge in stages out of the existing block and street fabric and into a cul-de-sac archipelago that in later phases would come to resemble, in many respects, the contemporary Megalopolis. I will return to this important resemblance in the conclusion.

Beyond the temporal dimension, a second, key characteristic of the project is the transformation of a monocentric, centralized organization into a polycentric conurbation consisting of thirty-nine discontinuous nuclei, each structured by a spine-based figure. While Hilberseimer's transformation of Rockford into a linear city is demonstrative of a key modernist paradigm -an open-ended, linear organizationthe project does more than demonstrate his commitment to a modern paradigm. It was, rather, an integrated response to the riverine setting itself. In other words, what prompted the linear reorganization of Rockford was not an interest in a linear city per se, but in the creation of a reciprocal relation between urban and natural forms. This reciprocity between a linear urbanism and a linear river valley was in response to the author's perceived imbalance between an urbanism that spreads out of a single center like an arbitrary spill and the natural context upon which it was spilt. That context is not abstract but is defined by the greater watershed surrounding the Rock River. The watershed is formed by the highly varied topography of a long river valley including the river, its tributaries and its adjoining wetlands, forests and associated fauna. Hilberseimer's project reveals that this landscape is a biological/geological network or super organism which any urban settlements must integrate with through a process of functional imitation. By imagining the city as a part of this greater biological/geological network, the replanning of the city would imitate the functional adaptation of an organism to its ecosystem. Through this imitation, Hilberseimer staged a transformation of Rockford from a mechanically reproduced gridiron town into an integrated species of urban organism fully adapted to its natural setting.

The specifics of the project spell out the details of Hilberseimer's mimetic strategies. The first panel of the project shows the existing condition of Rockford as an aggregated gridiron infrastructure surrounding the original ford in the Rock River. Using two intermediate stages, the city is gradually transformed street-by-street, from a centralized fabric of continuous blocks and streets into a linear aggregation of discontinuous spine fragments. The first transitional phase isolates what will become the primary north/south traffic artery and begins to distinguish it from the mesh of surrounding streets. This road will follow the river, crossing and recrossing it as some sort of man-made equivalent to the flow of water and sediment. In the second stage of the plan, the grid demolition continues and new street construction commences. A second, primary east/west road is then established in the south and the downtown grid is substantially cleared out around the river. The original ford is restored as the length of the river begins a process of retreat and, one imagines, rewilding, bringing natural forces back into play. In the third stage of the proposal, the primary curvilinear armature has been connected up to the south and the four primary axes that previously connected the city to the 
hinterland have been removed. As grid demolition proceeds, the banks of the river are completely rehabilitated with all urban infrastructure being pulled back out of the floodplain save the bridge over the city's original ford. In this process a second north/south axis is established to organize the remaining infrastructure east of the river. Thirty-nine new spine nuclei are initiated at this stage including the provision for three new nodes for heavy industry downwind from population areas. In the "final", phase the continuous blocks and streets of the gridiron are eliminated and a new pattern of open-ended, linear aggregation is established. Mimicking the processes of urban transformation that evolve over long extended (and variable) periods of time, Hilberseimer staged a lyrical reconciliation between the industrial city and the natural environment in which it exists. Linear patterns of urban settlement are now set to grow in balance with the sum of the natural forces surrounding the Rockford River valley.

Looking at the "final" stage of the Rockford proposal, one is struck by what a discontinuous polynuclear urbanism can do and what a continuous gridded fabric cannot. Primary among its capabilities is that of integration into its ecological context. Unlike the continuous gridiron, Hilberseimer's linear aggregation was capable of responding to existing conditions as the inherent discontinuity of its spine units could easily shift orientation to accommodate complex topography and adapt to the geological scale of the watershed. Furthermore, its built-in discontinuity allowed for the accommodation of these natural features at all levels of the organization. Like a comb open to the unique temperatures and breezes of the riparian biota, each and every new residential street now terminated at the river's edge.

Hilberseimer sought an integration between an urbanism of parts and the complex ecological networks that made up its riverine setting. Analogous to an organism, it would adapt, over time, to a specific environment through a design process that looks much like the evolutionary process that produced its setting. In the end, the room in the building, the building in the city and the city in the region would be conceived as a "holistic and unified relational structure" fully adapted to its greater environment. Fulfilling the basic definition of ecology as a relationship between organisms and between organisms and their natural context, we see the relational logic evident in the segments of a finger played out at a regional scale.

CONCLUSION: ANTICIPATING THE SUBURBAN ERA
The Rockford plan is "functional" by analogous association with its natural surroundings in the manner of a complex environmental organism. This is an example of ecological planning that is pitched in a cultural rather than a technical key, as distinct from the more common examples of "green" planning that invariably fail to transcend technocratic priorities. In other words, they fail to challenge the deeply held anthropocentric biases inherent in a strictly technical approach. In his well-known collection of essays, Down the River, the eco-poet Edward Abbey railed against these biase by explicitly associating them with the process of resource extraction: "I detest the word "resource". How could a wild river, part of nature's bloodstream, ever come to be regarded primarily as a damned resource? As if it were no more than a vein of coal, a field of cabbages, a truckload of cow manure?". Resources are, of course, extractions from 
the larger set of relationships of which coal, cabbages and manure are but a part. New Rockford is as much a restoration project as it is an exercise in modernist urbanism. Pulling back from the river's floodplain and making space for its complex, bottomland biota to return is not just a new idea for the human occupation of the landscape, it is a liberation of the river from its subjugation as a resource.

It is no accident that the later phases of Hilberseimer's New Rockford reproduce the familiar spine-based pattern of contemporary suburban development. The cul-de-sac spines seen in American mass housing tracts and in the Radiant Cities of Asia and Europe are programmatic monocultures structured by discontinuous, spine-based nuclei of Hilberseimer's "invention". Like a "field of cabbages", the residential subdivisions, office parks, shopping malls, megachurches, airports and housing estates lack the lyricism of Rockford's choreography, yet their spine-based substrate carries the potential of functional imitation that Hilberseimer encoded in all of his work.

Having explored the spine since the late twenties, Hilberseimer came to correctly identify it as the unique organizational substrate of modern urbanism. In projects such as New Rockford or Lafayette Park, Hilberseimer speculated that the spine would come to replace the gridded extensions of blocks and streets that had characterized urbanism for centuries. Since the moment of its first articulation, this speculation has been wholly borne out. As we move through the twenty-first century, spine-based urbanism has come to structure a greater and greater proportion of the built environment. Having not reproduced traditional blocks and streets for over seventy years, spine-based urbanism today accounts for up to $75 \%$ of the built environment,

The shared, spine-based structure of both New Rockford and the banal suburban monocultures of the past half century is of great consequence for urban reform today. For the first time, functional imitation takes us beyond the overt scenography of a bucolic idyll. Curving streets and verdant parks construct the outward appearance of natural systems while ignoring its inner logic. Hilberseimer's project suggest that a sophisticated, non-scenographic mode of imitation is available to urban design based on an interactive network of natural and urban forces rather than its leafy outward appearance. While the relation between the Rockford redesign and the found state of contemporary suburban development is strained, one can nevertheless argue that the broad environmental ambitions of Hilberseimer's project lies latent in the ubiquitous spine-based substrate already in place. In other words, our suburban environments are primed for a badly needed conceptual overhaul.

It is not a coincidence that our mental habits reflect the priorities of the extraction economy; "capitalism is a way of organising nature". This organization is based on a process of commodification which extracts raw material from the networks in which they are embedded and transforms them into discrete objects of consumption. Our need to materially and conceptually understand the networks to which objects belong speaks to the importance of imposing limits on material production. It also speaks to the revaluation of spectacular form-making. Moving beyond the extraction economy requires a cultural shift that eschews the crude objectifications of nature and culture as poles of a binary argument. Following the logic of the integrated ecosystem, design must come to imitate, not the objects of nature, but its intricate functional relationships. RA 


\section{Notes}

01. HEIDEGGER, Martin, Being and Time, trans, Macquarie and Robinson, New York, Harper \& Row, 1962, p. 100.

02. LATOUR, Bruno, Making Things Public, Cambridge, MIT Press, 2005, p. 16.

03. ALLEN, Stan, "From Object To Field", Architectural Design, Architecture after Geometry, AD Profile, n. 127, 1998, p. 25.

04. Mies van der Rohe, Inaugural Address, Illinois Institute of Technology, 1938, in: MERTINS, Detlef, "Living in a Jungle: Mies, Organic Architecture, and the Art of City Building", Mies In America, ed. Phyllis Lambert, New York, Abrams, 2001, p. 620.

05. MOORE, Jason W., "Capitalism as a Way of Organizing Nature", 2014. http:// jasonwmoore.wordpress.com/2014/03/22/ capitalism-as-a-way-of-organizing-nature/ accessed 25 May, 2018.

06. MERTINS, Detlef, "Living in a Jungle", p. 619 .

07. Ibid, p. 618.

08. ABBEY, Edward, quoted in David Boyd, The Rights of Nature: A Legal Revolution That Could Save the World, Toronto, ECW Press, 2017. 